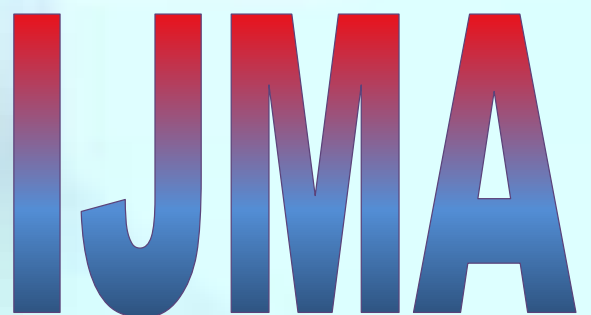

INTERNATIONAL

Journal of MEdical

\section{ARTS}

Volume 3, Issue 1 (Winter 2021)

http://ijma.journals.ekb.eg/

Print ISSN: 2636-4174

Online ISSN: 2682-3780

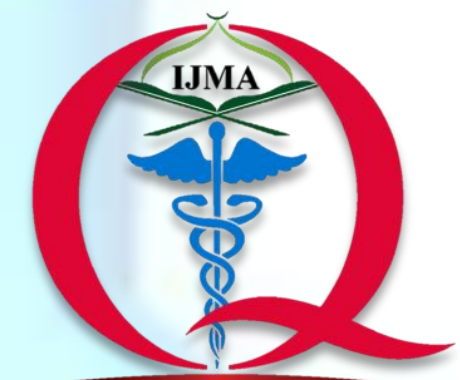

International Jounnal of Medical Arts

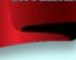





Available online at Journal Website
https://ijma.journals.ekb.eg/
Main Subject [Pediatrics, Radiology]

Original article

\title{
A comparison between the Use of Chest X-ray and Lung Ultrasound in the Diagnosis of Pneumonia in Children in Damietta Governorate
}

\author{
Ahmed Mohamed Karkar [1]; Mohamed Abdelsalam Zannoun[2]; Ahmed Mohamed Fekry Eldeek[3]; Magdy \\ Mohamed Ashmawy Sakr[2]
}

Department of Pediatrics, Damietta General Hospital, Ministry of Health, Egypt ${ }^{[1]}$

Department of Pediatrics, Damietta Faculty of Medicine, Al-Azhar University, Egypt[2]

Department of Radiology, Damietta Faculty of Medicine, Al-Azhar University, Egypt[3]

Corresponding author: Ahmed Mohamed Karkar

Email: karkor2018@yahoo.com

Received at: August 14, 2020; Revised at: October 10, 2020; Accepted at: October 13, 2020

DOI: 10.21608/ijma.2020.36693.1154

\section{ABSTRACT}

Background: Pneumonia is a life-threatening disease in children. Diagnosis of pneumonia is mainly clinical. However, some clinical features may be subtle or not specific. Lung ultrasound (LUS) might be used as a diagnostic tool in pneumonia as it is an easily accessible and safe imaging technique.

Aim of the work: This study aimed to investigate the role of lung ultrasound in diagnosing pneumonia compared to chest x-ray in children

Subjects and methods: This cross-sectional study was carried out at the general pediatric wards and pediatric intensive care units [PICUs], Department of Pediatrics, Al-Azhar University Hospital [Damietta]. It included 120 patients who were clinically diagnosed to have pneumonia. Each legal guardian signed informed consent. Then, everyone was subjected to chest x-ray and lung ultrasound, and results were compared.

Results: Sonographic findings in children with pneumonia as consolidation was detected in 114/120 (95.6\%), air bronchogram in 104/120 (86.7\%), fluid bronchogram 37(31.1\%), multiple B-lines in 68/120 (56.7\%), pleural effusion in 29/120 (24.4\%). The lung ultrasound [LUS] showed higher diagnostic accuracy (94.45\%), sensitivity (95.6\%), and specificity (93.3\%). There was a statistically significant good agreement between LUS and chest X-ray [CXR].

Conclusion: LUS is safe, accurate, and more sensitive for the diagnosis of suspected pneumonia in the pediatric age group and had the advantage of reducing radiation hazard when compared to chest X-ray

Keywords: Pneumonia; Lung Ultrasound; Air-bronchogram; Chest X rays; Children.

This is an open-access article registered under the Creative Commons, ShareAlike 4.0 International license [CC BY-SA 4.0] [https://creativecommons.org/licenses/by-sa/4.0/legalcode]

Please cite this article as: Karkar AM, Zannoun MA, Eldeek AMF, Sakr MMA. A comparison between the Use of Chest X-ray and Lung Ultrasound in the Diagnosis of Pneumonia in Children in Damietta Governorate. IJMA 2021; 3[1]: 938-945. DOI: 10.21608/ijma.2020.36693.1154

* Main subject and any subcategories have been classified according to the research topic. 


\section{INTRODUCTION}

Community-acquired pneumonia (CAP) is the most common cause of death in children below 5 years ${ }^{[1]}$. In Egypt, pneumonia and other acute respiratory infections are responsible for at least $10 \%$ of deaths in children under 5 years ${ }^{[2]}$. Pneumonia is an infection that pathologically affects the lung parenchyma and involves alveoli in variable proportions resulting in the air replacement in the alveoli by exudative fluid or pus ${ }^{[3]}$. Unlike adults, CAP's diagnosis in children depends mainly on clinical criteria. These criteria rely on the child's age and include high temperature, tachypnea, difficulty in breathing, cough, tachycardia, wheeze, abdominal pain, or chest pain [4].

Based on international guidelines, a chest $x$ ray (CXR) is not routinely needed in all children with mild clinical symptoms and signs of CAP, but only in severe cases requiring hospital admission or in cases resistant to medical therapy. In addition, lateral $x$-rays were not always performed [5]. A confluent opacification in the X-ray image is considered pneumonia's radiologic hallmark. It is also confirmed by interstitial infiltrates, which are considered evidence of pneumonia[]]. There are two major disadvantages in using CXRs for the diagnosis of pneumonia in children; the first is radiation exposure and, the second is the great intraobserver and interobserver variability in the interpretation of the findings[]]. Current data suggest that the risk of fatal cancer in children due to radiation exposure is not negligible because of great life expectancy and high tissue radio-sensitivity ${ }^{[8]}$.

Starting treatment without confirming the diagnosis or knowing the underlying pathology's extent usually results in antibiotics' overuse. Therefore, alternative free radiation diagnostic tools should be encouraged when evaluating CAP in children, and LUS offers this advantage ${ }^{[4]}$. For a long time, the lung was considered off-limits for an ultrasound. However, recently, LUS has been growing in multiple settings and evaluated different lung conditions, including diagnosing CAP of children. Many studies have reported its reliability and accuracy in diagnosing this pathology in infants and children[9-12]. Recently Pereda et al. ${ }^{[13]}$ conducted a meta-analysis, which confirmed that LUS has an overall sensitivity of $96 \%$ and a specificity of $93 \%$ for the diagnosis of pneumonia in children. Other studies also promoted lung ultrasound to be the first choice or recommend it as a valid alternative tool to replace CXR ${ }^{[12,14]}$.

\section{AIM OF THE WORK}

This study aims to investigate the role of LUS in the diagnosis of pneumonia as compared to CXR in children clinically diagnosed with pneumonia at the general pediatric wards and pediatric intensive care units [PICUs] of Al Azhar university hospital [Damietta].

\section{PATIENTS AND METHODS}

This is a comparative cross-sectional study, including 120 patients aged 12 to 60 . They were enrolled from patients attending the Pediatric Department, PICUs [Al-Azhar university hospital, Damietta], Egypt, between April 2018 and October 2019.

Inclusion criteria: Clinical signs and pneumonia symptoms ${ }^{[4]}$ (fever, cough, lethargy, chest pain, symptoms and signs of respiratory distress including tachypnea, retractions, grunting, and cyanosis in association with auscultatory findings associated with diminished air entry, fine crepitation, and bronchial breathing). Children aged below 5 years. Presence of clinical driven $x$-ray. Availability of a pediatric sonographer expert in LUS.

Exclusion criteria were: patients with co-existing chronic lung disease or predisposing congenital abnormalities, unwilling parents/guardians, and contraindications with radiological exposure as chromosomal breakage syndromes, e.g. (AtaxiaTelangiectasia, fragile $X$ syndrome, and Wiskott Aldrich syndrome). All included patients were subjected to the following: Full history taking regarding demographic data included age, sex, 
residence, smoking habits in the families, and history of chest infection. Complete physical examination including vital signs; temperature, heart rate, blood pressure, respiratory rate, and capillary refilling time. Assessment of respiratory distress signs: tachypnea, subcostal and intercostals retraction, working accessory muscles of respiration, grunting, and cyanosis[5]. The systemic examination focused on chest examination, including inspection, percussion, and auscultation.

Laboratory investigations: On admission, a blood sample was taken to assess total white blood cell count with differential count, hemoglobin, platelet count, and serum C-reactive protein (CRP).

Chest radiography: Posteroanterior CXR was done on the day of admission with appropriate measurements and technical parameters according to (patient's weight or age) to achieve minimum radiation exposure and providing sufficient diagnostic quality. Children aged from 12 to 24 months underwent CXR in the supine position, whereas older children, aged from 2 to 5 years, underwent posteroanterior CXR in the standing position according to the British Thoracic Society guidelines, lateral radiographs were not obtained[5].

Chest ultrasound: Lung ultrasound was done after plain radiography on the same day by a certified pediatric radiologist blinded to the CXR. Chest ultrasound is performed using appropriate transducers and frequencies, according to the age and the body build of the child $(5-8 \mathrm{MHz}$ micro convex, 5-12 MHz linear array, and 3-5 MHz convex transducers) most effective in visualizing the chest wall, pleura, and the lung peripheral parenchyma. The technique consisted of longitudinal scans, from top to bottom, along the anatomical lines of the thorax (parasternal, midclavicular axillary, and paravertebral lines) as well as axial scans along with the intercostal spaces. In most cases, dorsal regions were examined in the sitting position, while anterior regions were examined in the supine position. Ultrasound findings associated with pneumonia were recorded, such as hypoechoic areas of various sizes and shapes, air bronchograms, fluid bronchograms, B-lines, the vascular pattern within the consolidation, and pleural effusion. ${ }^{[15]}$.

Ethical consideration: The study was approved by the Institutional Ethical and Research Committee [Al-Azhar university, Faculty of Medicine, Damietta], and oral consent was taken from at least one parent or caregiver of children included in the study. The study was carried out following the Declaration of Helsinki adopted in June 1964 and revised in October 2000.

Statistical analysis: Analysis of data was done using Statistical Package for Social Science version 20 (SPSS Inc., Chicago, IL, USA). Quantitative variables were described in the form of mean and standard deviation. Qualitative variables were described as number and percent. Qualitative variables were compared using chi-square (X2). A $P$ value $<0.05$ is considered significant.

\section{RESULTS}

A total of 120 cases of pneumonia included in this study, 77 (64.4\%) were males, and 43 $(35.6 \%)$ were females, their ages ranged from 12 to 60 months with mean age $24.11 \pm 7.42$ months. Their weight ranged from 9 to $20 \mathrm{~kg}$, and mean weight is $12.66 \pm 2.13 \mathrm{~kg}$ and height ranged from 75 to $105 \mathrm{~cm}$ with a mean height of $82.04 \pm$ $8.02 \mathrm{~cm} .85(71.1 \%)$ of patients are urban residents, while $35(28.9 \%$ ) live in rural areas. $75(62.2 \%)$ of patients are passive smokers, while $45(37.8 \%)$ had no smoking habit in their families [Table 1].

In CXR, 107 patients (88.90\%) were positive for consolidation, and only 5 patients (4.2\%) had pleural effusion in CXR [Table 2]. In LUS, 114 patients (95.6\%) were positive for consolidation, 104 patients $(86.7 \%)$ were positive for air bronchogram, fluid bronchogram were detected in 37 patients $(31.1 \%)$, multiple B-lines were detected in 68 patients $(56.7 \%)$, pleural effusion was detected in 29 patients (24.4\%) [Table 3]. There was a statistically significant good agreement between LUS and CXR [Table 4]. Consolidation limited to one lobe presented in 74 
patients $(62.6 \%)$ by CXR, while 80 patients $(66.6 \%)$ showed consolidation limited to one lobe by LUS. Consolidation in more than one lobe presented 33 patients $(37.4 \%)$ by CXR, while 34 patients $(28.3 \%)$ showed

Table [1]: Demographic and clinical characteristics of all studied patients.

\begin{tabular}{|l|c|c|}
\hline \multirow{2}{*}{} & \multicolumn{2}{|c|}{ Pneumonia group [N=120] } \\
\cline { 2 - 3 } & Mean \pm SD & Min. - Max. \\
\hline Age (Months) & $24.11 \pm 7.42$ & $12-60$ \\
\hline Sex [Female/ male (No,\%)] & \multicolumn{2}{|c|}{$43(35.6 \%) / 77(64.4 \%)$} \\
\hline Weight (kg) & $12.66 \pm 2.13$ & $9-20$ \\
\hline Length/Height (cm) & $82.04 \pm 8.02$ & $75-105$ \\
\hline Residence [Urban/Rural (No/\%)] & \multicolumn{2}{|c|}{$85(71.1 \%) / 35(28.9 \%)$} \\
\hline Passive smoking [Positive/Negative (No/\%)] & \multicolumn{2}{|c|}{$75(62.2 \%) / 45(37.8 \%)$} \\
\hline
\end{tabular}

Table [2]: Chest $X$ ray findings in the studied patients.

\begin{tabular}{|l|c|c|}
\hline \multirow{2}{*}{} & \multicolumn{2}{|c|}{ Pneumonia group [n=120] } \\
\cline { 2 - 3 } & Positive & Negative \\
\hline Chest X-ray Role & $107(88.90 \%)$ & $13(11.10 \%)$ \\
\hline Lung consolidation & $107(88.90 \%)$ & $13(11.10 \%)$ \\
\hline Pleural effusion & $5(4.2 \%)$ & $115(95.8 \%)$ \\
\hline
\end{tabular}

Table [3]: Findings of Lung Ultrasound in the studied patients.

\begin{tabular}{|l|c|c|}
\hline \multirow{2}{*}{} & \multicolumn{2}{|c|}{ Pneumonia group [No. = 120] } \\
\cline { 2 - 3 } & Positive & Negative \\
\hline LUS Role & $114(95.6 \%)$ & $6(4.4 \%)$ \\
\hline Hepatization & $114(95.6 \%)$ & $6(4.4 \%)$ \\
\hline Dynamic Air Bronchogram & $104(86.7 \%)$ & $16(13.3 \%)$ \\
\hline Fluid Bronchogram & $37(31.1 \%)$ & $83(68.9 \%)$ \\
\hline Pleural effusion & $29(24.4 \%)$ & $91(75.6 \%)$ \\
\hline Multiple B lines & $68(56.7 \%)$ & $52(43.3 \%)$ \\
\hline
\end{tabular}

Table [4]: Agreement between LUS and CXR

\begin{tabular}{|c|c|c|c|c|c|}
\hline & \multicolumn{2}{|c|}{ LUS } & \multirow[t]{2}{*}{ Total } \\
\hline & & & $+v e$ & -ve & \\
\hline \multirow[t]{7}{*}{ CXR } & \multirow[t]{3}{*}{$+v e$} & $\mathrm{~N}$ & 107 & 0 & 107 \\
\hline & & $\%$ LUS & $93.9 \%$ & $0.0 \%$ & \\
\hline & & $\%$ CXR & $100 \%$ & $0.0 \%$ & \\
\hline & \multirow[t]{3}{*}{-ve } & $\mathrm{N}$ & 7 & 6 & 13 \\
\hline & & $\%$ LUS & $6.1 \%$ & $100 \%$ & \\
\hline & & $\%$ CXR & $53.8 \%$ & $46.2 \%$ & \\
\hline & \multicolumn{2}{|c|}{ Total } & 114 & 6 & \\
\hline \multicolumn{2}{|c|}{ Kappa } & \multicolumn{2}{|c|}{0.726} & & \\
\hline
\end{tabular}

Table [5]: Comparison between CXR and LUS in the detection of Lobar distribution of consolidation among pneumonia patients.

\begin{tabular}{|c|c|c|c|c|}
\hline \multirow[t]{2}{*}{ Number of consolidation lesion } & \multirow[t]{2}{*}{ CXR [no. = 107] } & \multirow[t]{2}{*}{ LUS[no. $=114]$} & \multicolumn{2}{|c|}{ Chi-square test } \\
\hline & & & $X^{2}$ & $\mathrm{P}$-value \\
\hline $\begin{array}{l}\text { Consolidation confined to } 1 \text { lobe (No/\%) } \\
\text { Yes } \\
\text { No }\end{array}$ & $\begin{array}{l}74(62.6 \%) \\
33(37.4 \%)\end{array}$ & $\begin{array}{l}80(66.7 \%) \\
34(28.3 \%)\end{array}$ & 0.027 & 0.87 \\
\hline $\begin{array}{l}\text { Consolidation in more than } 1 \text { lobe ( } \mathrm{No} / \%) \\
\text { Yes } \\
\text { No }\end{array}$ & $\begin{array}{l}33(37.4 \%) \\
74(62.6 \%)\end{array}$ & $\begin{array}{l}34(28.3 \%) \\
80(66.7 \%)\end{array}$ & 0.027 & 0.87 \\
\hline
\end{tabular}

CXR: chest $x$-ray, LUS: lung ultrasound, $X^{2}$ : Chi-square test, $P>0.05$ : Non-Significant, $P<0.05$ : Significant 


\section{DISCUSSION}

Early diagnosis and treatment of pneumonia in children are critically affected by the related short- and long-term health outcomes. However, clinical examination is considered highly sensitive, but it lacks specificity and can lead to overdiagnosis and overuse of antibiotics [16]. However, CXR is considered the test of choice to confirm pneumonia's clinical suspicion. The major limitation of CXR is the risk of ionizing radiation, as the radiological risk is cumulative in nature. A previous study suggested that hepatoblastoma risk may increase due to repeated exposure to chest $X$-rays [17].

Our cross-sectional study included 120 children with pneumonia ranging from 12 to 60 months with male predominance $77 \mathrm{child}$ (64.4\%). This agrees with Elmashad et al.[18] who reported male to female ratio was 1.8:1 in patients with pneumonia. Also, Siziya et al. ${ }^{[19]}$ showed a considerable predominance of males $59.7 \%$ over females among children with pneumonia. Moreover, Falagas et al.[20] reported a male predominance in children with lower respiratory tract infections; the investigator explained the difference in the prevalence of infections between males and the anatomical variations of the respiratory tract. In contrast Montasser et al.[21] reported in his study a comparable ratio, with slight female predominance $(51 \%)$.

The current study showed that $75 / 120$ of studied children with pneumonia had been exposed to second-hand smoking. This comes in agreement with Elmashad et al.[18] who reported that $62.2 \%$ of studied cases were exposed to passive smoking. Also, Azad et al.[22] reported that $50.5 \%$ of the children with respiratory tract infections were exposed to second-hand smoking. The most dangerous and most common indoor environmental pollutant children can be exposed to is passive smoking exposure. Passive smoking causes paralysis of cilia in respiratory mucosa, which allows accumulation of mucus, and promotes goblet cell growth, leading to an increase in mucus. Also, passive smoking increases respiratory illnesses like asthma, bronchitis, pneumonia, bronchiolitis, and otitis media, even sudden infant death, as the effect of tobacco smoke exposure was found to be more prominent and hazardous in infants [23,24].

In our study LUS detected consolidation in 114 patient (95.6\%) and was normal in 6 cases and detected pleural effusion in 29 cases (24.4\%) while, CXR was able to detect consolidation in 107 patient (88.90\%) and missed 13 cases with pneumonia and only detect 5 cases with pleural effusion. CXR may fail to detect these lesions either due to their relatively small sizes at the early stage of the disease, or these lesions are difficult to reach as, beyond the heart or mediastinum. Additional lateral chest radiographs may help to increase the detection rate for hidden pneumonic patches. Six patients were negative for pneumonia on LUS. The reasons why LUS did not detect the pneumonic patches are the same as CXR; it may be because the lesions were not large enough to extend to the pleura, or the lesions were in difficult locations beyond the reach of the ultrasound beam, such as the supraclavicular fossa, the axillary region, and the area behind the scapula. Our results are concordant with the results of Ho et al.[25] who also found that chest radiography able to detect $151(92.6 \%)$, while LUS detected 159 (97.5\%) and pleural effusion in 43 patients (27.0\%) out of 163 patients with pneumonia. Additionally, Elmashad et al. ${ }^{[18]}$ reported that consolidation was diagnosed by CXR in $88.9 \%$ and effusion in $15.6 \%$ of pneumonia cases, whereas LUS was diagnostic in $95.6 \%$ of pneumonia cases, and pleural effusion was detected in $24.4 \%$ of cases . Copetti et al.[26] reported that among 60 hospitalized children with CAP, $83.3 \%$ had abnormal CXR while $100 \%$ had LUS findings suggestive of CAP. Also, Caiulo et al.[27] reported that among 89 hospitalized children, $92 \%$ had abnormal CXR while $98.8 \%$ had LUS suggestive of CAP. Recently, a study on 40 Egyptian children done by El-Sayed et al. [28], reported that LUS was able to detect consolidations in $29(73 \%)$ patients as compared to $18(45 \%)$ patients detected by CXR of total 40 patients. (23\%) out of the 40 cases were positive for pleural effusion by 
CXR, versus 19 patients (48\%) by LUS. LUS was normal in 11 patients while CXR failed to detect abnormality in 22 patients.

In our study LUS was higher than CXR in detecting consolidation in one lobe or more than one lobe; however, there was no significant difference between both techniques $(p<0.05)$. Comparable findings were reported by El-Sayed et al.[28]. There was no statistically significant difference found between CXR and LUS in detecting consolidation in one lobe or more than one lobe $p=0.06$. In contrast, Sartori and Tombesi[29] reported more than one lung consolidation in their sonographic finding in $26 / 89$ patients versus $6 / 89$ cases detected by CXR. In previous studies, the positive air bronchogram rates in patients with pneumonia ranged from $86.7 \%$ to $97 \%$ [15,30]. Our study had similar results as104 (86.7\%) of our patients had air bronchogram on LUS. Conducting airways packed with exudate are represented by the fluid bronchogram, which occurs less frequently than the air bronchogram as the rate of fluid bronchogram was reported to range from $0 \%$ to $8.1 \%$ in adults $[15,30]$. However, in our study, the positive rate of fluid bronchogram was $31.1 \%$. This may be attributed to the fact that conducting airways in children are narrower and smaller, so the exudate can obstruct them more easily, sometimes leads to lung collapse. Also, in ElSayed et al.[28] study air bronchograms were positive in the consolidated areas detected in 9 patients $(23 \%)$ by CXR, while, by LUS, air bronchograms were positive in 25 patients $(63 \%)$; moreover, the study done by Hajalioghli et al.[31] declared that the diagnostic accuracy of LUS in their research had increased significantly by the presence of air bronchogram as an important sonographic finding that indicates the presence of pneumonia rather than atelectasis. Diffuse comet-tail artifacts or B-lines in LUS are signs of the alveolar interstitial syndrome. Although these artifacts are present around an isolated alveolar consolidation, the absence of a B-line could be useful in excluding any opacity in CXR[32]. In our study, the positive rate of comet-tail (B-lines) artifacts around the pneumonia were $(56.7 \%)$, which is close to previously reported data by Caiulo et al. [27], who detected B-lines in $(59 \%)$ of studied children. In the diagnosis of pneumonia by LUS, the consolidation is also associated with air bronchogram within the lesions; B-lines around them increases the specificity of a diagnosis of pneumonia, whereas, the disappearance of the B-lines or alteration in the pattern of lines during follow up by LUS is a sign of resolution and lung re-aeration[33]. Similar results regarding LUS findings, was found in the study of $\mathrm{Ho}$ et al.[25] which included 163 children with pneumonia and reported that from 159 pneumonia patients diagnosed by LUS B-lines was seen in 81 (50.9\%) patients. $149(93.7 \%)$ patients had a positive air bronchogram, and $32(20.1 \%)$ had a positive fluid bronchogram on the LUS scan.

In our study, LUS had a sensitivity of $95.6 \%$ and specificity of $93.3 \%$, compared to the sensitivity of $88.9 .0 \%$ and specificity of $86.7 \% \%$ by CXR. Similarly, Pereda et al. [13], found that LUS had a sensitivity of $96 \%$ and specificity of $93 \%$. Recently a meta-analysis was done by Balk et al. ${ }^{[34]}$ on twelve studies ${ }^{[9-}$ 12,14,25-27,35-38] including 1510 patients showed that LUS had a mean sensitivity of $95.5 \%$ (93.6-97.1) and specificity of 95.3\% (91.1-98.3) while, CXR had a sensitivity of $86.8 \%$ (83.390.0 ) and specificity of $98.2 \%$ (95.7-99.6).

Our study's limitations were the relatively small sample size, and we did not perform computed tomography chest, which is the standard gold test in CXR negative cases to detect any radiological abnormalities.

Conclusion: This study suggests that lung ultrasonography is more accurate and sensitive than chest X-ray to diagnose suspected cases of community acquired pneumonia in the pediatric age group. It offers better detection of consolidations and other pneumonia associated lung abnormalities, thus reducing radiation exposure in this age group.

Financial and Non-Financial Relationships and Activities of Interest

None 


\section{REFERENCES}

1. Global Burden of Disease Pediatrics Collaboration, Kyu HH, Pinho C, Wagner JA, Brown JC, Bertozzi-Villa A, Charlson FJ, et al. Global and National Burden of Diseases and Injuries Among Children and Adolescents Between 1990 and 2013: Findings From the Global Burden of Disease 2013 Study. JAMA Pediatr. 2016 Mar; 170 (3):267-87. [DOI: 10.1001/jamapediatrics.2015.4276].

2. El Seify MY, Fouda EM, Ibrahim HM, Fathy MM, Al-Husseiny Ahmed A, Khater WS, et al. Microbial etiology of community-acquired pneumonia among infants and children admitted to the pediatric hospital, Ain Shams University. Eur J Microbiol Immunol. 2016;6 (3): 206-14. [DOI: 10.1556/1886.2016.00022]

3. Mackenzie G. The definition and classification of pneumonia. Pneumonia. 2016; 8(1):14. [DOl: 10.1186/s41479-016-0012-z].

4. Bradley JS, Byington CL, Shah SS, Alverson B, Carter ER, Harrison $C$, et al. Executive Summary: The Management of CommunityAcquired Pneumonia in Infants and Children Older Than 3 Months of Age: Clinical Practice Guidelines by the Pediatric Infectious Diseases Society and the Infectious Diseases Society of America Pediatric Community Pneumonia Guidelines. Clin Infect Dis. 2011; 53 (7): 617. [DOI: 10.1093/cid/cir625].

5. Harris M, Clark J, Coote N, Fletcher P, Harnden A, McKean M, et al. British Thoracic Society guidelines for the management of community acquired pneumonia in children: update 2011. Thorax. 2011; 66 (Suppl 2):ii1-23. [DOI: 10.1136/ thoraxjnl-2011-200598].

6. Cherian T, Mulholland EK, Carlin JB, Ostensen H, Amin R, Campo MD, et al. Standardized interpretation of paediatric chest radiographs for the diagnosis of pneumonia in epidemiological studies. Bull World Health Organ. 2005; 83:353-9. [DOI: 10.1093/cid/cix082].

7. Johnson J, Kline JA. Intraobserver and interobserver agreement of the interpretation of pediatric chest radiographs. Emerg Radiol. 2010; 17 (4): 285-90. [DOI: 10.1007/s10140-009-0854-2].

8. Alzen G, Benz-Bohm G. Radiation protection in pediatric radiology. Deutsches Ärzteblatt Int. 2011; 108 (24): 407. [DOI: 10.3238/arztebl. 2011.0407].

9. Guerra M, Crichiutti G, Pecile P, Romanello C, Busolini E, Valent $F$, et al. Ultrasound detection of pneumonia in febrile children with respiratory distress: a prospective study. Eur J Pediatr. 2016. 175 (2):163-70. [DOI: 10.1007/s00431-015-26118. 163-70]
10. lorio G, Capasso M, Prisco S, De Luca G, Mancusi C, Laganà B, Piscopo MA, Comune V. Lung ultrasound findings undetectable by chest radiography in children with community-acquired pneumonia. Ultrasound Med Biol. 2018; 44 (8): 1687-93. [DOI: 10.1016/j. ultrasmedbio.2018.04. 007].

11. Yadav KK, Awasthi S, Parihar A. Lung ultrasound is comparable with chest roentgenogram for diagnosis of community-acquired pneumonia in hospitalised children. Indian J Pediatr. Indian J Pediatr. 2017 Jul;84(7):499-504. [DOI: 10.1007/s12098-017-2333-1].

12. Yilmaz HL, Özkaya AK, Sarı Gökay S, Tolu Kendir Ö, Şenol H. Point-of-care lung ultrasound in children with community acquired pneumonia. Am J Emerg Med. 2017 Jul; 35(7):964-969. [DOI: 10.1016/j.ajem.2017.01.065].

13. Pereda MA, Chavez MA, Hooper-Miele CC, Gilman RH, Steinhoff MC, Ellington LE, et al. Lung ultrasound for the diagnosis of pneumonia in children: A meta-analysis [Internet]. Pediatr. 2015; 135;714-22. [DOI: 10.1542/peds.2014-2833].

14. Boursiani C, Tsolia M, Koumanidou C, Malagari A, Vakaki M, et al. Lung ultrasound as first-line examination for the diagnosis of communityacquired pneumonia in children. Pediatr Emerg Care. 2017; 33: 62-6. [DOI: 10.1097/ PEC. 0000000000000969].

15. Reissig A, Gramegna A, Aliberti S. The role of lung ultrasound in the diagnosis and follow-up of community-acquired pneumonia. Eur J Intern Med. 2012; 23 (5): 391-7. [DOI: 10.1016/j.ejim.2012. 01. 003].

16. Zimmerman DR, Kovalski N, Fields $\mathrm{S}$, Lumelsky D, Miron D. Diagnosis of childhood pneumonia: clinical assessment without radiological confirmation may lead to overtreatment. Pediatr Emerg Care 2012; 28 (7): 646-9. [DOI: 10.1097/PEC. 0b013e31825cfd53].

17. Turcotte LM, Georgieff MK, Ross JA, Feusner $\mathrm{JH}$, Tomlinson GE, Malogolowkin MH, et al. Neonatal medical exposures and characteristics of low birth weight hepatoblastoma cases: a report from the Children's Oncology Group. Pediatr Blood Cancer. 2014; 61 (11): 2018-23. [DOI: 10. 1002/pbc.25128]

18. Elmashad G, Bahbah W, Mousa W, Shalaby M. Study of lung ultrasono-graphy as a diagnostic tool in childhood pneumonia. Menoufia Med J. 2019; 32 (3): 1043. [DOI: 10.4103/mmj.mmj_800_17].

19. Siziya S, Muula AS, Rudatsikira E. Diarrhoea and acute respiratory infections prevalence and risk factors among under-five children in Iraq in 2000. Ital J Pediatr. 2009 Apr 25;35(1):8. [DOI: 10.1186/1824-7288-35-8] 
20. Falagas ME, Mourtzoukou EG, Vardakas KZ. Sex differences in the incidence and severity of respiratory tract infections. Respir Med. 2007; 101 (9): 1845- 63. [DOI: 10.1016/j.rmed.2007.04. 011].

21. Montasser N, Hela R, Rezq R. Assessment and Classification of Acute Respiratory Tract Infections among Egyptian Rural Children. Br J Med Med Res. 2012 Jan 10;2(2):216-27.

22. Yeasir Azad SM, Bahauddin KM, Uddin H, Parveen S. Indoor Air Pollution and Prevalence of Acute Respiratory Infection among Children in Rural Area of Bangladesh. J Biol Agric Healthc. 2014; 4 (2): 60-71.

23. Savitha MR, Nandeeshwara SB, Kumar MP, Raju CK. Modifiable risk factors for acute lower respiratory tract infections. Indian J Pediatr. 2007 74(5):477-82. [DOI: 10.1007/s12098-007-0081].

24. Peat JK, Keena V, Harakeh Z, Marks G. Parenta smoking and respiratory tract infections in children. Paediatr Respir Rev. 2001;2(3):207-13. [DOI: 10.1053/ prrv.2001.0142].

25. Ho MC, Ker CR, Hsu JH, Wu JR, Dai ZK, Chen IC. Usefulness of lung ultrasound in the diagnosis of community-acquired pneumonia in children. Pediatr Neonatol. 2015; 56 (1): 40-5. [DOI: 10 1016/j.pedneo.2014.03.007].

26. Copetti R, Cattarossi L. Ultrasound diagnosis of pneumonia in children. Radiol Med. 2008; 113 (2): 190-8. [DOI: 10.1007/s11547-008-0247-8].

27. Caiulo VA, Gargani L, Caiulo S, Fisicaro A, Moramarco F, Latini G, et al. Lung ultrasound characteristics of community-acquired pneumonia in hospitalized children. Pediatr Pulmonol. 2013; 48 (3): 280-7. [DOI: 10.1002/ppul. 22585].

28. Mohamed AE, Kamel OF, Ghazy MS. Accuracy of lung ultrasonography in diagnosis of community acquired pneumonia as compared to chest $\mathrm{x}$-ray in pediatric age group. Egyp J Hospital Med. 2018; 72 (8): 4977-83. [DOI: 10.12816/EJHM.2018. 10273]

29. Sartori S. Emerging roles for trans-thoracic ultrasonography in pulmonary diseases. World $\mathrm{J}$ Radiol. 2010 Jun 28;2 (6):203-14. [DOI: 10.4329/ wjr.v2.i6.203].

30. Reissig A, Kroegel C. Sonographic diagnosis and follow-up of pneumonia: a prospective study. Respiration. 2007; 74(5):537-47. [DOI: 10.1159/ 000100427].
31. Hajalioghli $\mathbf{P}$, Nemati $\mathbf{M}$, Dinparast Saleh L, Fouladi DF. Can chest computed tomography be replaced by lung ultrasonography with or without plain chest radiography in pediatric pneumonia? J Thorac Imaging. 2016; 31 (4): 247-52. [DOI: 10. 1097/RTI. 0000000000000209].

32. Volpicelli G, Caramello V, Cardinale L, Mussa A, Bar F, Frascisco MF. Detection of sonographic $B$-lines in patients with normal lung or radiographic alveolar consolidation. Med Sci Monit. 2008; 14(3): CR122-8. [PMID: 18301355].

33. Bouhemad B, Brisson H, Le-Guen M, Arbelot C, Lu Q, Rouby JJ. Bedside ultrasound assessment of positive end-expiratory pressureinduced lung recruitment. Am J Respir Crit Care Med. 2011 Feb 1;183(3):341-7. [DOI: 10.1164/ rccm.201003-03690C].

34. Balk DS, Lee C, Schafer J, Welwarth J, Hardin J, Novack V, et al. Lung ultrasound compared to chest X-ray for diagnosis of pediatric pneumonia: A meta-analysis. Pediatr Pulmonol. 2018; 53 (8): 1130-1139. [DOI: 10.1002/ppul. 24020].

35. Dianova TI, Dianova TI. Ultrasound monitoring \& age sonographic characteristics of communityacquired pneumonia in children. Sovrem Tehnol v Med. 2015; 7 (2): 113-8. [DOI: 10.17691/ stm2015.7.2.15].

36. Shah VP, Tunik MG, Tsung JW. Prospective evaluation of point-of-care ultrasonography for the diagnosis of pneumonia in children and young adults. JAMA Pediatr. 2013;167(2):119-25. [DOI: 10.1001/2013.jamapediatrics.107].

37. Iorio G, Capasso M, De Luca G, Prisco S, Mancusi C, Laganà B, Comune V. Lung ultrasound in the diagnosis of pneumonia in children: proposal for a new diagnostic algorithm. PeerJ. 2015;3:e1374. [DOI: 10.7717/ peerj.1374].

38. Reali F, Sferrazza Papa GF, Carlucci P, Fracasso P, Di Marco F, Mandelli M, et al. Can lung ultrasound replace chest radiography for the diagnosis of pneumonia in hospitalized children? Respiration. 2014;88(2):112-5. [DOI: 10.1159/ 000362692]. 


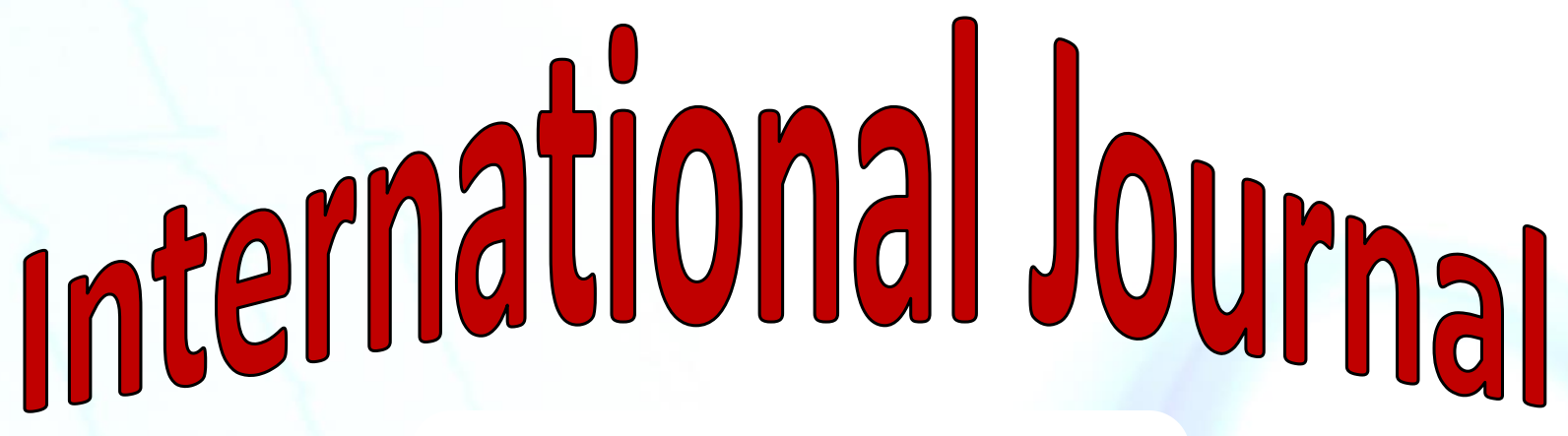

https://ijma.journals.ekb.eg/

Print ISSN: 2636-4174

Online ISSN: 2682-3780

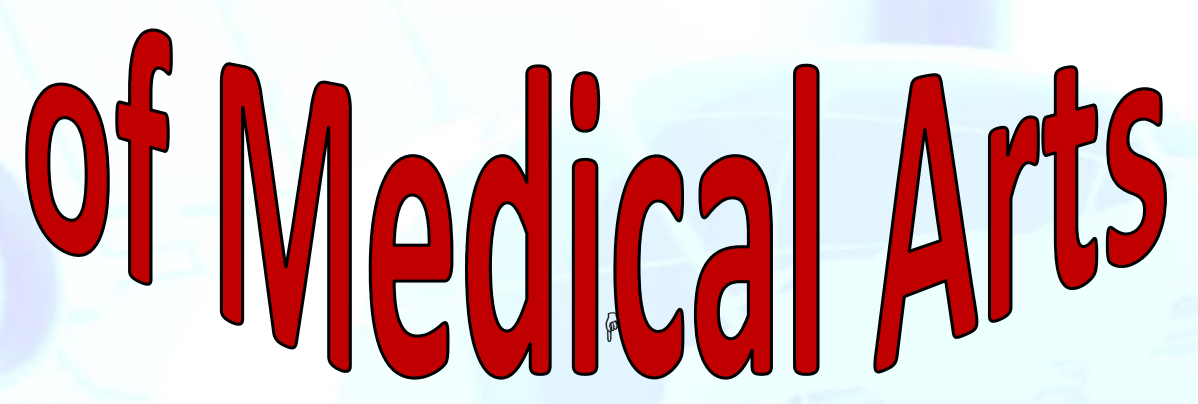

